\title{
Economic Assessment of Low Humidity Peat Production Practice
}

\author{
Elena Chertkova $^{1}$ and Victoria Sizova ${ }^{1}$ \\ ${ }^{1}$ Tver State Technical University, 22 Af. Nikitin Street, 170026, Tver, Russia
}

\begin{abstract}
The article presents a milled peat production practice based on deep bed drying up to a harvesting moisture content of $35 \%$. The task of the developed technology is to minimize and stabilize the harvesting humidity in the field drying of peat, thereby reducing the time and thermal impact on the peat organic matter during a forced finish drying. The applied method of peat extraction provides for variable milling depth and differentiation of cycle harvesting to increase the number of cycles and the harvester seasonal output. An economic feasibility study has been carried out by the method of determining the operating costs per ton of a marketable product for each technological operation. It consists in a comparative assessment of two technological processes: the production practice based on intensification of milled peat drying up to a harvesting moisture content of $35 \%$ and the conventional harvesting of milled peat with moisture content of $45 \%$. The developed technology of milled peat extraction makes it possible to ensure the required quality parameters in terms of humidity $(\leq 35 \%)$ and to preserve natural bituminous components. Based on the economic assessment results, it has been found that there is a slight increase in operating costs per ton of a marketable product in comparison with the conventional practice.
\end{abstract}

\section{Introduction}

At present, in the mining industries of economically developed countries, the emphasis is on the production practices that can ensure the qualitative characteristics of raw material as early as at the geotechnological stage to reduce significantly the costs of its further processing and manufacture competitive products.

The main quality characteristics regulated by current peat production normative documents are humidity and ash content in the extracted peat. If the ash content is largely determined by natural characteristics of a peat deposit, the harvesting humidity depends entirely on the adopted peat extraction practice. The technological development of fragmented peat extraction for the purpose of fuel production and raw materials for advanced chemical processing is toward intensifying the natural drying process that is focused on reducing the harvesting humidity. As a rule, the moisture content of milled fuel peat that is supplied to a consumer is $45-50 \%$. Even if we take the average initial humidity of milled peat as $47 \%$ or $0.89 \mathrm{~kg} / \mathrm{kg}$ in terms of wetness, then $0.70 \mathrm{~kg}$ of moisture per kilogram of dried peat under factory conditions has to be removed, which is associated with significant heat energy consumption $[1,2]$. In addition, this process is accompanied by an 
increase in temperature and time of exposure to peat, which leads to a change in the chemical group composition of peat and the loss of some valuable organic components [3].

The task of the developed technology is to minimize and stabilize a harvesting humidity in the field drying of peat, thereby reducing the time and temperature effect on its organic matter during a forced drying.

The production practice is represented by the following technological operations: peat deposit milling; fragmented peat tedding; peat harvesting by pneumatic machines; stacking.

The main variable parameter in the methods used for extraction of milled peat is a milling depth. Cycle peat deposit milling is performed by a dynamic cutting drum after precipitation to the depth of $25-30 \mathrm{~mm}$ provided that a layer of $45-50 \mathrm{~mm}$ thick is formed (Figure 1). In the second and subsequent cycles after precipitation, a cutting drum makes a layer of the fragmented peat that has remained in a production field and of the peat additionally milled at the depth of no more than 10-12 $\mathrm{mm}$ [1].

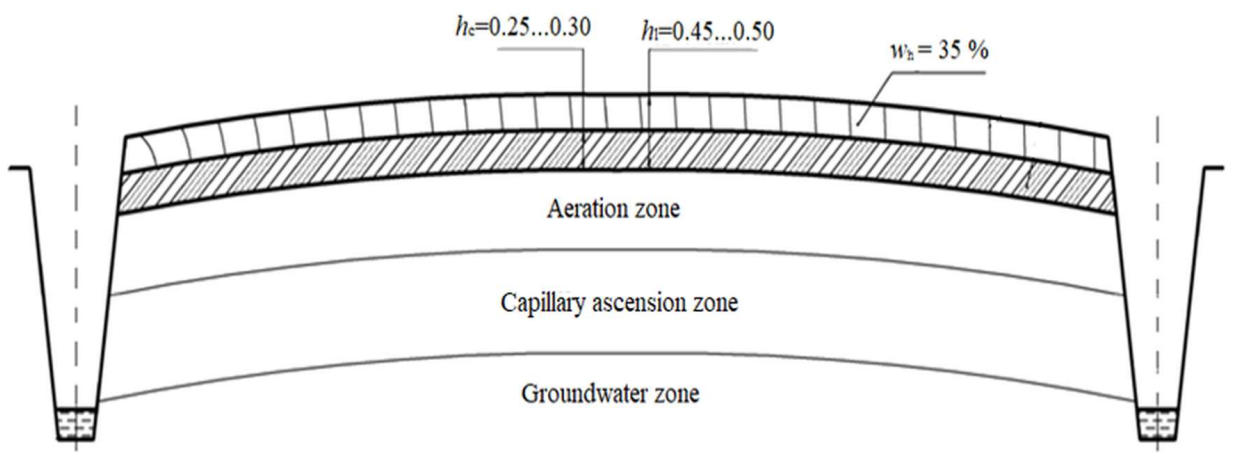

Fig.1. Peat bed pattern.

The method of fragmented peat drying in a deep bed is conducted in two layers. The maximum evaporation of moisture occurs in the upper layer, and the lower one is critical, it largely prevents the negative impact of the deposit on a peat drying (Figure 2). The critical layer is made $30 \mathrm{~mm}$ thick in the upland peat deposit, and it is $25 \mathrm{~mm}$ thick in the lowland peat deposit [4].

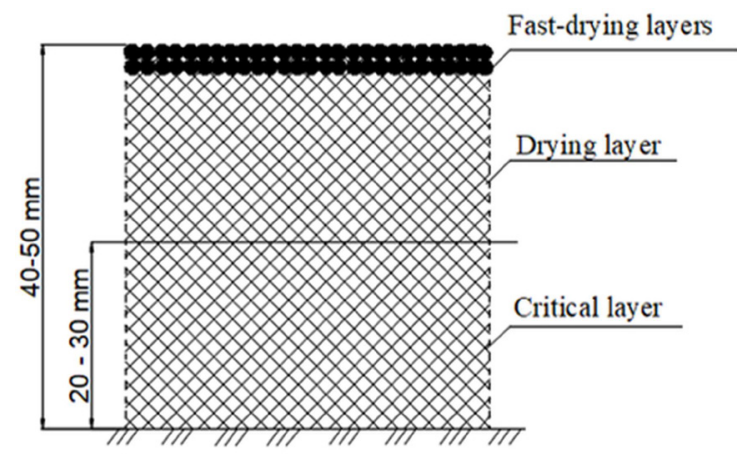

Fig.2. Deep bed drying.

The next operation in a technological cycle is tedding. To intensify drying within a singleday cycle duration, one tedding is performed if the category of drying is high and two-time tedding in case of medium and weak drying categories. Tedding in the top of a fragmented peat layer is performed at the depth of $20-25 \mathrm{~mm}$. 
It is advisable to harvest the top layer of milled peat by pneumatic machines. The pneumatic method of harvesting has significant advantages over the mechanical one.

Firstly, the lightest dry particles, that is, with the lowest humidity are sucked first. Secondly, it excludes the complementary peat deposit milling, which does not increase a harvesting humidity [5-7].

After harvesting, the peat deposit is milled to a depth of 10-12 mm together with the remains of the previous peat in order to create a layer of $45-50 \mathrm{~mm}$ thick for the next cycle.

The purpose of the economic feasibility study is to make a comparative assessment of two technological processes: the production practice based on intensification of milled peat drying up to a harvesting moisture content of $35 \%$ (the developed method) and the pneumatic harvesting of milled peat with moisture content of $45 \%$ (current or conventional method).

The costs of the peat deposit drainage, preparation and servicing of production sites do not depend on the technological process of peat extraction, therefore, they have not been taken into account in the economic feasibility study. With the same qualitative characteristics of a peat deposit and the equal production schedule, the differences in economic assessment of the technological processes are determined by values of the milled peat cyclic and seasonal harvests, quantity of marketable products and productivity of technological machines. Therefore, to conduct the economic assessment of the proposed practice of extracting milled peat with no more than $35 \%$ humidity, the methodology of determining operating costs per ton of marketable products is taken for each technological operation of the process.

Cost estimate includes the following input data:

- location area - Pskov region;

- type of peat deposit - upland;

- peat decay degree $-30 \%$;

- stumpiness of peat deposit $\geq 1 \%$;

- storage loss - 7\% for peat with $45 \%$ moisture content and $10 \%$ - for peat with $35 \%$ moisture content;

- number of a single-day technological cycles - 36;

- milling depth of harvesting the peat with $45 \%$ moisture content $-8.25 \mathrm{~mm}$; average milling depth of creating a thick layer of peat with $35 \%$ moisture content $-11 \mathrm{~mm}$;

- technological machines: milling machine - BF-6.5; tedding machine - FCS-9.6; harvester - MPTU-30; stacker - AMKODOR-30; tractors: for milling and harvesting - MTZ-1221, for tedding - MTZ-82;

- design cycle harvesting: for $45 \%$ moisture content peat $-12.36 \mathrm{t} / \mathrm{ha}$, for peat with intensification of drying to moisture content of $35 \%-11.95 \mathrm{t} / \mathrm{ha}$;

- re-tedding in a cycle: for peat drying in deep layers - 1.5 , and for $45 \%$ moisture content peat -1 .

\section{Method used}

The operational performance of machines for milling, tedding and harvesting is determined by formula:

$$
S=0,1 v_{\mathrm{T}} \cdot K_{\mathrm{v}} \cdot b_{\mathrm{d}} \cdot K_{\mathrm{w}} \cdot K_{\mathrm{c}} \cdot K_{\mathrm{m} . \mathrm{t}}
$$

where $\mathrm{v}_{\mathrm{T}}$ is theoretical design (passport) speed of tractor or self-propelled vehicle, $\mathrm{km} / \mathrm{h} ; K_{\mathrm{v}}$ is velocity factor; $b_{\mathrm{d}}$ is design operating tool width; $K_{\mathrm{w}}$ is utilization factor of design operating tool width; $K_{\mathrm{c}}$ is cycle time factor; $K_{\mathrm{m} . t}$ is factor of available machine time.

The operational performance of the stacking machine is determined by formula:

$$
V=V_{\mathrm{p}} \cdot \gamma_{\mathrm{b}} \cdot K_{\mathrm{m} . t .}
$$


where $V_{\mathrm{p}}$ is technical performance, $\mathrm{m}^{3} / \mathrm{h} ; \gamma_{\mathrm{b}}$ is bulk density of milled peat of harvest moisture, $\mathrm{t} / \mathrm{m}^{3}$.

The speeds for milling a peat deposit are determined by the engine power. The speeds for harvesting milled peat with pneumatic machines are calculated on the assumption of entire dried peat harvesting and are checked by the power of a tractor engine.

To calculate the cost of a machine shift in technological operations, a preliminary assessment of operating costs is carried out [8].

The specific fuel consumption for each operation is determined by formula:

$$
m_{\mathrm{f}}=m_{\mathrm{en}} \cdot P_{\mathrm{e} n} \cdot K_{\mathrm{m} . \mathrm{t} .} \cdot K_{\mathrm{f}} \cdot K_{\mathrm{en} .1} \cdot t_{\mathrm{sh}}
$$

where $m_{\mathrm{en}}$ is specific fuel consumption by the internal combustion engine, $\mathrm{kg} /(\mathrm{kW} \cdot \mathrm{h}) ; P_{\mathrm{en}}$ is engine power, $\mathrm{kW} ; K_{\mathrm{m} . t}$ is factor of available machine time; $K_{\mathrm{f}}$ is coefficient that takes into account the idle operation of engine and flittings; $K_{\text {en.l }}$ is coefficient taking into account the total engine load; $t_{\mathrm{sh}}$ is shift duration, $\mathrm{h}$.

The cost of diesel fuel $\left(C_{\mathrm{f}}\right)$ is determined by formula:

$$
C_{\mathrm{f}}=m_{\mathrm{f}} \cdot C \cdot K_{1}
$$

where $C$ is cost of a kilogram of diesel fuel, RUB; $K_{1}$ is coefficient that takes into account the consumption of lubricants.

The cost of basic wages and salaries with payroll charges and incentive payments $\left(C_{\mathrm{W}}\right)$ are determined by formula:

$$
C_{\mathrm{w}}=T_{\mathrm{h}} \cdot K_{\mathrm{in}} \cdot K_{\mathrm{s}} \cdot t_{\mathrm{sh}}
$$

where $T_{\mathrm{h}}$ is hourly rate of wage, RUB; $K_{\text {in }}$ is coefficient taking into account incentive (bonus) payment; $K_{\mathrm{s}}$ is coefficient that takes into account social fund and pension contributions.

The depreciation cost $\left(C_{\mathrm{D}}\right)$ of a tractor and technological machines are calculated as follows:

$$
C_{\mathrm{D}}=\frac{C_{\mathrm{ch}} \cdot P_{\mathrm{m}} \cdot K_{\mathrm{tr}}}{100\left(P_{\text {sh.o }}+P_{\text {sh.a }}\right)}
$$

where $C_{\mathrm{D}}$ is depreciation charges; $P_{\mathrm{m}}$ is machine price including VAT, RUB; $K_{\mathrm{tr}}$ is coefficient taking into account transport costs and installation work; $P_{\text {sh.o }}$ is number of shifts per year in peat extraction operations; $P_{\text {sh.a }}$ is additional number of tractor shifts.

The number of shifts per year in peat extraction operations $\left(P_{\text {sh.o }}\right)$ can be calculated using the following formula:

$$
P_{\text {sh.o }}=P_{\mathrm{c} . \mathrm{s}} \cdot \tau_{\mathrm{c}} \cdot m_{\mathrm{cr}} \cdot m
$$

where $P_{\mathrm{c} . \mathrm{s}}$ is standard number of cycles; $\tau_{\mathrm{c}}$ is planned cycle duration, days; $m_{\mathrm{cr}}$ is planned repetitiveness of operation in a cycle; $m$ is planned repetitiveness of operation due to precipitation.

The maintenance costs are determined using the depreciation cost formula, but the deductions are taken as $15 \%$ for a tractor and $12 \%$ for machines.

Costs per ton of marketable peat for milling, tedding and harvesting operations $\left(C_{\mathrm{i}}\right)$ are determined by formula:

$$
C_{\mathrm{i}}=\frac{C_{\mathrm{m} . \mathrm{h}} \cdot n \cdot m}{S \cdot q_{\text {凹 }}\left(1-\frac{\delta_{\mathrm{st}}}{100}\right)}
$$


where $C_{\mathrm{m} . \mathrm{h}}$ is cost of a machine-hour, RUB; $n$ is repetitiveness of operation in a cycle; $m$ is repetitiveness of operation due to precipitation; $S$ is operational productivity, ha / h; $\delta_{\mathrm{st}}$ is loss of finished products during storage, $\%$.

The stacking costs per ton of commercial peat $\left(C_{\mathrm{st}}\right)$ are determined as follows:

$$
C_{\mathrm{st}}=\frac{C_{\mathrm{m} . \mathrm{h}} \cdot K_{\mathrm{st}}}{V \cdot \gamma_{\mathrm{b}}\left(1-\frac{\delta_{\mathrm{st}}}{100}\right)},
$$

where $K_{\text {st }}$ is stacking factor; $\gamma_{\mathrm{b}}$ is bulk density of milled peat of harvest moisture, $\mathrm{t} / \mathrm{m}^{3}$.

\section{Results and Discussions}

Working capacity of machines are calculated by formula (1) and presented in Table 1.

Table 1. Calculations of machine working capacity

\begin{tabular}{|c|c|c|c|c|c|c|c|c|c|c|c|c|c|c|}
\hline \multirow{2}{*}{$\begin{array}{c}\text { Production } \\
\text { operations }\end{array}$} & \multicolumn{9}{|c|}{$\begin{array}{c}\text { Production practice with deep bed } \\
\text { drying }\left(\mathbf{w h}_{\mathbf{h}}=35 \%\right)\end{array}$} \\
\cline { 2 - 15 } & $\begin{array}{c}\mathrm{U}_{\mathrm{T}}, \\
\mathrm{km} / \\
\mathrm{h}\end{array}$ & $K_{\mathrm{v}}$ & $\begin{array}{c}B_{\mathrm{d}}, \\
\mathrm{m}\end{array}$ & $K_{\mathrm{w}}$ & $K_{\mathrm{c}}$ & $K_{\mathrm{m} . \mathrm{t}}$ & $\begin{array}{c}S \\
\mathrm{ha} / \\
\mathrm{h}\end{array}$ & $\begin{array}{c}\mathrm{U}_{\mathrm{T}}, \\
\mathrm{km} / \\
\mathrm{h}\end{array}$ & $K_{\mathrm{v}}$ & $\begin{array}{c}B_{\mathrm{d},} \\
\mathrm{m}\end{array}$ & $K_{\mathrm{w}}$ & $K_{\mathrm{c}}$ & $K_{\mathrm{m} . \mathrm{t} .}$ & $\begin{array}{c}S \\
\mathrm{ha} / \\
\mathrm{h}\end{array}$ \\
\hline Milling & 10.9 & 0.92 & 6.5 & 0.94 & 0.79 & 0.83 & 4.84 & 12.6 & 0.92 & 6.5 & 0.94 & 0.82 & 0.83 & 5.77 \\
\hline Tedding & 11.4 & 0.97 & 9.6 & 0.95 & 0.70 & 0.85 & 6.82 & 11.4 & 0.97 & 9.6 & 0.95 & 0.85 & 0.85 & 7.34 \\
\hline Harvesting & 5.87 & 0.95 & 3.65 & 1.0 & 0.77 & 0.85 & 1.33 & 4.75 & 0.95 & 3.65 & 1.0 & 0.87 & 0.85 & 1.22 \\
\hline
\end{tabular}

Table 1 shows that in conventional production practice $\left(w_{\mathrm{h}}=45 \%\right)$, the working capacity of machines in milling operations is $13.5 \%$ higher due to a higher speed and a shallower milling depth as well as a higher cycle time factor compared to the production practice with deep bed drying $\left(w_{\mathrm{h}}=35 \%\right)$. The working capacity in tedding operations is $7 \%$ higher in the in conventional production practice, which is stipulated by the fact that its cycle time factor is higher by 17.6. The working capacity of a pneumatic harvester is $9 \%$ higher in milled peat production practice with deep bed drying due to the weight reduction of peat with $35 \%$ harvest humidity.

The applied method of peat extraction provides for a variable milling depth and differentiation of cycle harvesting, which allows increasing the number of cycles by $25 \%$ and the seasonal output of the harvester by $18 \%$. At the same time, under favorable weather conditions, there are no areas unharvested. The increase in cycle harvesting is significantly influenced by more intensive moisture removal from the dried layer with the aid of better aeration, which ultimately leads to enhancement of moisture removal from peat particles in the form of steam.

The study of the bitumen content in cotton grass-sphagnum peat with a decay rate of 25 $30 \%$ extracted by the proposed technology shows (Table 2 ) its increase by $1.7 \ldots 2$ times within the required temperature range in comparison with the conventional peat production practice.

A decrease in the harvesting moisture content of milled peat during a natural drying on the aerated bedding in the extraction technology with a critical layer of 25-30 mm ensures the maximum retention of high-mobility bituminous components in the raw material owing 
to reducing the time and thermal impact on peat organic matter during subsequent forced finish drying.

Table 2. Bitumen content in organic matter of peat when it is dried in a shaft-mill dryer (AC-1)

\begin{tabular}{|c|c|c|c|c|}
\hline \multirow{2}{*}{ No } & \multirow{2}{*}{$\begin{array}{c}\text { Magnitude of temperature effect } \\
\text { on dried peat, K }\end{array}$} & \multicolumn{3}{|c|}{ Peat humidity at drier inlet, \% } \\
\cline { 3 - 5 } & & $\mathbf{3 5}$ & $\mathbf{4 5}$ & $\mathbf{5 0}$ \\
\cline { 3 - 5 } & 313 & 3.51 & 3.51 & 3.51 \\
\hline 1 & 473 & 4.15 & 2.43 & 2.08 \\
\hline 2 & 523 & 4.88 & 2.87 & 2.35 \\
\hline 3 & 553 & 5.86 & 3.45 & 2.98 \\
\hline 4 & 573 & 2.89 & 1.71 & 1.52 \\
\hline 5 & 673 & 1.74 & 1.02 & 0.89 \\
\hline 6 & & & & \\
\hline
\end{tabular}

To calculate the cost of a machine shift in technological operations, an estimate of operating costs is preliminary carried out according to formulas (2 - 9). All the calculations are summarized in Table 3.

Table 3. Summary results of calculating costs per ton of commercial peat of conditional humidity

\begin{tabular}{|c|c|c|c|c|c|c|}
\hline \multirow{2}{*}{$\begin{array}{c}\text { Production } \\
\text { operations }\end{array}$} & \multicolumn{3}{|c|}{$\begin{array}{c}\text { Production practice with deep bed } \\
\text { drying }\left(\boldsymbol{w}_{\mathbf{h}}=\mathbf{3 5} \%\right)\end{array}$} & \multicolumn{3}{|c|}{$\begin{array}{c}\text { Conventional production practice } \\
\left(\boldsymbol{w}_{\mathbf{h}}=\mathbf{4 5} \%\right)\end{array}$} \\
\cline { 2 - 7 } & $\begin{array}{c}\text { Production } \\
\text { per hour, } \\
\left(\text { ha, } \mathrm{m}^{3}\right)\end{array}$ & $\begin{array}{c}\text { Cost per } \\
\text { operator } \\
\text { hour, } \\
\text { RUB. }\end{array}$ & $\begin{array}{c}\text { Costs per } \\
\text { ton of } \\
\text { commercial } \\
\text { peat, RUB. }\end{array}$ & $\begin{array}{c}\text { Production } \\
\text { per hour, } \\
\text { (ha, m3) }\end{array}$ & $\begin{array}{c}\text { Cost per } \\
\text { operator } \\
\text { hour, } \\
\text { RUB. }\end{array}$ & $\begin{array}{c}\text { Costs per } \\
\text { ton of } \\
\text { commercial } \\
\text { peat, RUB. }\end{array}$ \\
\hline Milling & 4.84 & 2353.89 & 49.7 & 5.77 & 2353.89 & 39.0 \\
\hline Tedding & 6.82 & 1432.4 & 32.2 & 7.34 & 1432.4 & 18.7 \\
\hline Harvesting & 1.33 & 3756.8 & 262.6 & 1.22 & 3756.8 & 267.8 \\
\hline Stacking & 154.73 & 3432.75 & 20.0 & 179.03 & 3432.75 & 17.0 \\
\hline Total & & & 364.5 & & & 342.5 \\
\hline
\end{tabular}

Analyzing the results of cost calculations for individual operations per ton of marketable peat in terms of conditional humidity of $40 \%$, one can conclude that milled peat harvesting is the most costly production operation $(70 \ldots 80 \%$ of total costs). As compared to conventional production scheme, the cost of peat harvesting in the developed production practice based on the intensified deep bed drying is $2 \%$ lower. However, there is an increase 
in costs by $21.5 \%$ in milling operations and by $42.0 \%$ in tedding operations due to an increase in milling depth, a loss of machine capacity and a reduction of cycle time factor.

\section{Conclusions}

Thus, the production practice with deep bed drying makes it possible to extract milled peat with the best indexes of humidity and stabile chemical composition, as well as with the maximum retention of bitumen components in organic matter. Based on the economic assessment results, it has been found that there is a slight increase by $6.2 \%$ in operating costs per ton of a marketable product in comparison with the conventional practice.

\section{References}

1. E. Chertkova, V. Sizova, E3S Web of Conf., 15, 01048 (2018)

2. Panov V.V., Misnikov O.S., Gornyi Zhurnal, 7, 108-112 (2015)

3. O.S. Misnikov, O.V. Dmitriev, V.I. Popov, E.Yu. Chertkova, Polymer Science. Series D, 9, 1, 133-139 (2016)

4. Smirnov V.I., Misnikov O.S., Pukhova O.V., Gornyi Zhurnal, 7, 67-71 (2014)

5. A. Afanas'ev, A. Boltushkin, Colloid Journal of the Russian Academy of Sciences: Kolloidnyi Zhurnal, 58, 2, 139-144 (1996)

6. E. Kremcheev, D. Kremcheeva, Research Journal of Pharmaceutical, Biological and Chemical Sciences, 7, 3, 1284-1289 (2016)

7. V. Lebedev, O. Puhova, E3S Web of Conf., 21, 01023 (2017)

8. G. Alexandrov, A. Yablonev, E3S Web of Conferences, 21, 04011 (2017) 